\title{
Electromagnetic Properties of Substituted Barium Hexaferrites
}

\author{
J. Sláma, A. Grusková, V. JanČÁRIK, M. Štofoka
}

Faculty of Electrical Engineering and Information Technology

Slovak University of Technology

Ilkovičova 3, 81219 Bratislava, Slovakia

And A. GonzÁlez-Angeles

Facultad de Ingenieria, Universidad Autónoma de Baja California

Blvd. Benito Juárez s/n, Cp 21280 Mexicali, B.C., México

Substituted M-type ferrite $\mathrm{BaFe}_{12-2 x}\left(\mathrm{Me}_{1} \mathrm{Me}_{2}\right)_{x} \mathrm{O}_{19}, 0 \leq x \leq 0.6$ was prepared by both mechanical alloying and precursor method, where $\mathrm{Me}_{1}=$ $\mathrm{Co}, \mathrm{Ni}, \mathrm{Zn}, \mathrm{Sn}$ and $\mathrm{Me}_{2}=\mathrm{Ru}, \mathrm{Ti}, \mathrm{Zr}$, Sn. Magnetic phase purity, change of saturation polarization, Curie temperature, coercivity and magnetic susceptibility was studied as function of $x$. Attention was focused to results obtained for $(\mathrm{NiRu})_{x},(\mathrm{ZnRu})_{x}$, and $(\mathrm{SnRu})_{x}$ mixtures with low doping ratio $x$.

PACS numbers: 75.50.-y, 75.50.Vv, 81.20.Ev, 81.20.Ka

\section{Introduction}

M-type Ba-hexaferrite exhibits high specific saturation polarization $J_{s-m}$, strong uniaxial crystalline anisotropy $K_{1}$ and large coercivity $H_{\mathrm{c}}$. The strong uniaxial anisotropy of Ba-hexaferrite can be reduced by substitution of iron by other cations or mixture of cations. One aim of such substitution was to decline the magnetization of one of the sublattices from antiferromagnetic axis, i.e. to decline it from collinear and anticollinear ordering, respectively. The magnetocrystalline anisotropy becomes planar for a critical doping ratio $x_{\mathrm{c}}$ in some cases; these planar hexaferrites therefore become to be interesting materials for magnetic recording and microwave absorption devices. It is an efficient way for controlling the value of $H_{\mathrm{c}}$, while preserving the value of $J_{\mathrm{s}-\mathrm{m}}$. Various substitutions are possible in $\mathrm{BaFe}_{12} \mathrm{O}_{19}$ composition - big divalent cations on $\mathrm{Ba}^{2+}$ site and small trivalent cations, or divalent $\mathrm{Me}_{1}^{2+}$ together with tetravalent $\mathrm{Me}_{2}^{4+}$ ions combinations on the 
$\mathrm{Fe}^{3+}$ sites [1-5]. Substitutions of Fe ions have a big influence, directly affecting the magnetic structure.

The magnetic structure and properties of substituted M-type Ba-hexaferrites with composition $\mathrm{BaFe}_{12-2 x}\left(\mathrm{Me}_{1} \mathrm{Me}_{2}\right)_{x} \mathrm{O}_{19}$ were studied. Divalent $\mathrm{Me}_{1}=\mathrm{Co}, \mathrm{Ni}$, $\mathrm{Sn}, \mathrm{Zn}$ and tetravalent $\mathrm{Me}_{2}=\mathrm{Ru}, \mathrm{Ti}, \mathrm{Zr}$, Sn ion combinations were used in various compounds. The phase purity of the samples was evaluated by temperature dependence of initial susceptibility $\chi(T)$ and specific saturation polarization $J_{s-m}(T)$ [6] and it was verified by the Mössbauer spectroscopy and X-ray diffraction. The particle size and shape was observed under a transmission electron microscopy (TEM). The particles of all ferrite samples exhibit a plate-like, nearly hexagonal shape with diameter between 0.3 and $1.1 \mu \mathrm{m}$.

\section{Theory}

The intrinsic properties arise from the M-crystal structure - five distinct Fe-sublattices, which are coupled by super-exchange allowing only parallel $(\uparrow)$ or antiparallel $(\downarrow)$ orientation. The magnetic moments of the iron ions are arranged in parallel to hexagonal $c$-axis, but with opposite spin directions of the sublattices. Their mutual orientation is given by the known Gorter model: $12 \mathrm{k}(\uparrow), 4 \mathrm{f}_{1}(\downarrow)$, $4 \mathrm{f}_{2}(\downarrow), 2 \mathrm{a}(\uparrow)$ and $2 \mathrm{~b}(\uparrow)$. Three sites named $12 \mathrm{k}, 2 \mathrm{a}$, and $4 f_{2}$ have octahedral coordination, $4 \mathrm{f}_{1}$ has tetrahedral and $2 \mathrm{~b}$ site has a fivefold (bipyramidal) coordination. The resulting theoretical magnetic polarization $J$ at a temperature $T$ of $\mathrm{BaFe}_{12} \mathrm{O}_{19}$ per formula unit (f.u.) can be approximated by simple summation according to formula

$$
J(T)=6 m_{12 \mathrm{k}}(T)-2 m_{4 \mathrm{f1}}(T)-2 m_{4 \mathrm{f} 2}(T)+1 m_{2 \mathrm{a}}(T)+1 m_{2 \mathrm{~b}}(T),
$$

where $m_{n}$ is the magnetic moment of $\mathrm{Fe}^{3+}$ ion in $n$-th sublattice. Assuming a magnetic moment of $5 \mu_{\mathrm{B}}$ (Bohr magneton) per $\mathrm{Fe}^{3+}$ ion at $0 \mathrm{~K}$ we get a net polarization of $20 \mu_{\mathrm{B}}$ per f.u. for the pure $\mathrm{BaFe}_{12} \mathrm{O}_{19}$ at this temperature. It is in agreement with the observed saturation polarization for the pure compound $J_{\mathrm{s}}$. According to Eq. (1) one can expect a change of the net magnetic polarization when the $\mathrm{Fe}^{3+}$ ions in the spin-down sublattices $\left(4 \mathrm{f}_{1}, 4 \mathrm{f}_{2}\right)$ and/or spin up sublattices $(12 \mathrm{k}, 2 \mathrm{a}, 2 \mathrm{~b})$ are substituted.

\section{Results}

Influence of substitution to net polarization, magnetostructural anisotropy and coercivity $H_{\mathrm{c}}$ was investigated as well as possible limits of such approach. Change of magnetic polarization with doping ratio $x$ is expressed by the difference $\Delta J_{\mathrm{s}-\mathrm{m}}=J_{\mathrm{s}-\mathrm{m}}(x)-J_{\mathrm{s}-\mathrm{m}}(0)$, where $J_{\mathrm{s}-\mathrm{m}}(0)$ is the specific magnetic polarization of pure BaM ferrite $(x=0)$. This dependence for selected samples prepared by mechanical alloying $(\mathrm{Mx})$ is shown in Fig. 1a. It can be seen that $\Delta J_{\mathrm{s}-\mathrm{m}}$ increases with $x$ for $\mathrm{ZnRu}, \mathrm{NiRu}$, and SnRu substitutions presumably, because the magnetic moments in the spin-down sublattices $\left(4 \mathrm{f}_{1}, 4 \mathrm{f}_{2}\right)$ decrease more than those in the spin-up sublattices $(2 \mathrm{a}, 2 \mathrm{~b})$ (Eq. (1)). The $\mathrm{Ru}^{4+}$ ions seem to increase $\Delta J_{\mathrm{s}-\mathrm{m}}$, 

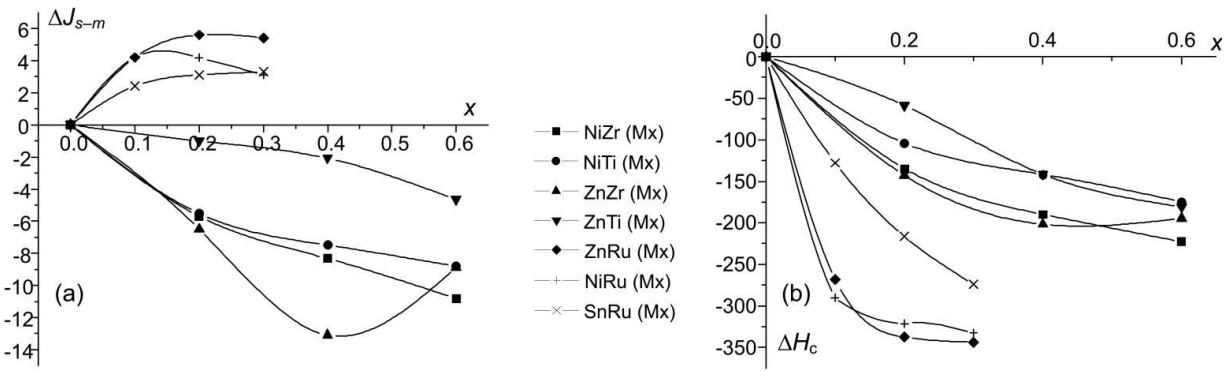

Fig. 1. Change of specific polarization $\Delta J_{\mathrm{s}-\mathrm{m}}$ (a) and coercivity $\Delta H_{\mathrm{c}}$ (b) as a function of $x$ for samples $(\mathrm{Mx})$.

it can also be attributed to a strong preference of $\mathrm{Zn}^{2+}$ to tetrahedral, $\mathrm{Ni}^{2+}$ and $\mathrm{Sn}^{2+}$ to octahedral coordination and no particular preference $\mathrm{Ru}^{4+}$ ions in $\mathrm{Me}_{1} \mathrm{Ru}$ mixtures.

The dependence of coercivity on $x$ is expressed by coercivity difference $\Delta H_{\mathrm{c}}(x)=H_{\mathrm{c}}(x)-H_{\mathrm{c}}(0)$, where $H_{\mathrm{c}}(0)$ is a coercivity of sample with $x=0$. Dependence $\Delta H_{\mathrm{c}}(x)$ for selected $\left(\mathrm{Me}_{1}, \mathrm{Me}_{2}\right)_{x}$ substituent ions is shown in Fig. 1b. The strong fall of $\Delta H_{\mathrm{c}}$ near $x=0.1$ and slight decrease in $\Delta H_{\mathrm{c}}$ observed near $x=0.3$ for $(\mathrm{NiRu})_{x}$ and $(\mathrm{ZnRu})_{x}$ leads to the conclusion that the reached value of $H_{\mathrm{c}}$ starts to correspond with planar anisotropy. This value of $H_{\mathrm{c}}$ change $(x \approx 0.3)$ is much lower than those of $x \approx 0.3 \div 0.6$ necessary for the $H_{\mathrm{c}}$ change of other $\left(\mathrm{Me}_{1}, \mathrm{Me}_{2}\right)_{x}$ ions. In order to understand the decrease in $\Delta H_{\mathrm{c}}$ with increasing $x$, ionic distribution in sites should be taken into account. The fivefold site $2 \mathrm{~b}$ has the strongest influence on the high anisotropy of $\mathrm{BaFe}_{12} \mathrm{O}_{19}$ ferrite. Structural refinements on $(\mathrm{NiRu})_{x}$ and $(\mathrm{ZnRu})_{x}$ substitutions show that $\mathrm{Ru}^{4+}$ preferentially substitutes $\mathrm{Fe}^{3+}$ ions on $2 \mathrm{~b}$ site for low $x$, and then on octahedral sites $4 f_{2}$ and 2a (for $\mathrm{Ni}$ ) or on the tetrahedral sites $4 \mathrm{f}_{1}$ (for $\mathrm{Zn}$ ).

Therefore, we attribute the rapid change of anisotropy and $H_{\mathrm{c}}$ in $(\mathrm{NiRu})_{x}$ and $(\mathrm{ZnRu})_{x}$ compounds to preferential occupation of $2 \mathrm{~b}$ site by $\mathrm{Ru}^{4+}$ cations. Moreover, we suppose that the nature of divalent cation $-\mathrm{Ni}^{2+}\left(3 d^{8}\right)$ or $\mathrm{Zn}^{2+}$ $\left(3 d^{10}\right)$ has influence but lower on the anisotropy change. This opinion is confirmed by the fact that the cationic distribution is the same in $(\mathrm{NiRu})_{x}$ as in $\left(\mathrm{Sn}^{2+} \mathrm{Ru}\right)_{x}$, but $\Delta H_{\mathrm{c}}$ values of $(\mathrm{SnRu})_{x}$ are significantly lower as compared with $(\mathrm{NiRu})_{x}$ and $(\mathrm{ZnRu})_{x}$. It is probably due to $\mathrm{Ni}^{2+}$ or $\mathrm{Zn}^{2+}$ having $3 \mathrm{~d}^{8}$ or $3 \mathrm{~d}^{10}$ orbitals and $\mathrm{Sn}^{2+}$ having $3 \mathrm{~d}^{10}, 4 \mathrm{~d}^{10}$ orbitals. This opinion could be supported by the fact, that $(\mathrm{CoRu})_{x}$ substitution [4] $\left(\mathrm{Co}^{2+}\right.$ has $3 \mathrm{~d}^{7}$ orbitals $)$ has the same effect on anisotropy as $(\mathrm{NiRu})_{x}$. In addition, $T_{\mathrm{c}}$ decreases with the substitution rate $x$ from $442^{\circ} \mathrm{C}(x=0)$ down to $426^{\circ} \mathrm{C}$ for $(\mathrm{ZnRu})_{0.3}, 435^{\circ} \mathrm{C}$ for $(\mathrm{NiRu})_{0.3}$ and $420^{\circ} \mathrm{C}$ for $(\mathrm{CoRu})_{0.3}$. Significantly lower value of $T_{\mathrm{c}}=389^{\circ} \mathrm{C}$ was found in the case of $(\mathrm{SnRu})_{0.3}$ substitution.

Furthermore presence of secondary phases containing spinel ferrite was found in $\chi(T)$ curves at temperature above $T_{\mathrm{c}}$ of the hexagonal phase for $\mathrm{NiMe}_{2}$ sub- 

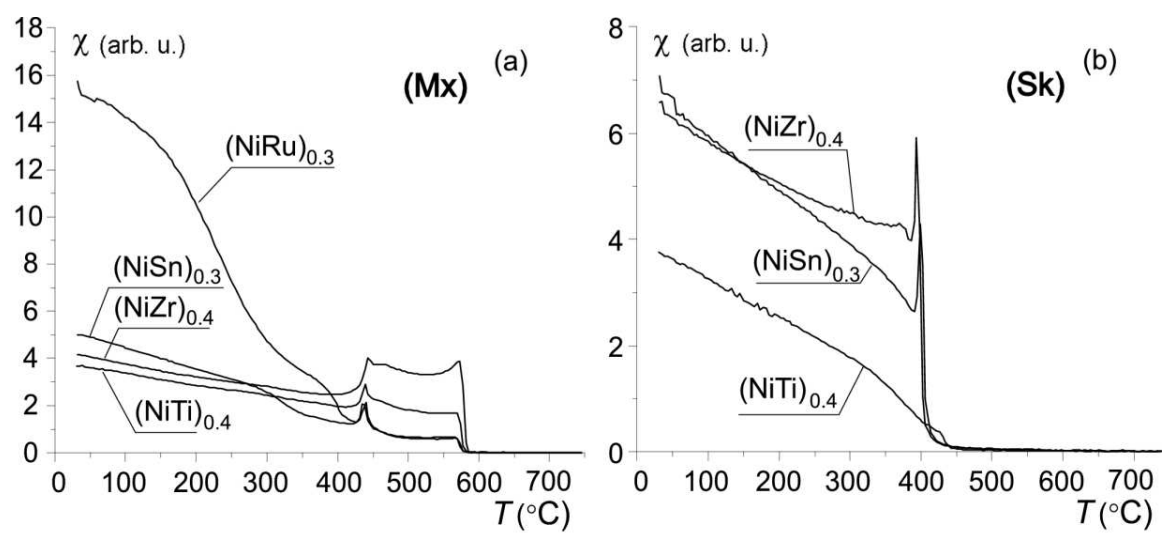

Fig. 2. Temperature dependence of magnetic susceptibility $\chi(T)$ of $\mathrm{NiMe}_{2}^{4+}$ prepared by $\mathrm{Mx}(\mathrm{a})$ and $\mathrm{Sk}(\mathrm{b})$.

stituted samples $\mathrm{Me}_{2}=\mathrm{Ti}, \mathrm{Zr}, \mathrm{Sn}, \mathrm{Ru}$ ) prepared only by mechanical alloying $(\mathrm{Fe} / \mathrm{Ba}=10.0)$, Fig. 2a. This phase was not detected by X-ray analysis; it is most likely the $\mathrm{NiFe}_{2} \mathrm{O}_{4}$ (or magnetite $\mathrm{Fe}_{3} \mathrm{O}_{4}$ ) compound, with $T_{\mathrm{c}} \approx 585^{\circ} \mathrm{C}$. On the other hand, no traces of spurious phases were found in BaM samples synthesized by the citrate precursor method $(\mathrm{Sk})(\mathrm{Fe} / \mathrm{Ba}=10.8)$ with $x$ up to 0.4 , Fig. 2b. Ni spinel ferrite was obtained by Turilli et al. [1] in $\mathrm{Sr}(\mathrm{NiTi})$ M-hexaferrite prepared by the metalorganic precursor method. Small doping rate of $x$ was sufficient in some cases - to achieve nearly planar anisotropy in $(\mathrm{NiRu})_{0.3}$ and $(\mathrm{ZnRu})_{0.3}$ mixtures with a low temperature coeficient of $H_{\mathrm{c}}$. Such ferrites could be very promising media for microwave devices and absorption at higher temperatures.

\section{Acknowledgments}

This work was supported by the VEGA of the Slovak Republic, the projects No. G-1/3096/06 and G-1/3189/06, respectively.

\section{References}

[1] G. Turilli, F. Licci, A. Paoluzi, T. Besagni, IEEE Trans. Magn. 24, 2146 (1998).

[2] D.H. Han, Z. Yang, H.X. Zeng, X.Z. Zhou, A.H. Morrish, J. Magn. Magn. Mater. 137, 191 (1994).

[3] M.V. Rane, D. Bahadur, S.D. Kulkarni, S.K. Date, J. Magn. Magn. Mater. 195, L 256 (1999).

[4] S. Pignard, H. Vincent, E. Flavin, F. Boust, J. Magn. Magn. Mater. 260, 437 (2003).

[5] G.B. Teh, S. Nagalingam, D.A. Jefferson, Math. Chem. Phys. 101, 1 (20158)07.

[6] R. Dosoudil, J. El. Eng. 53, 139, 10/S (2002). 